\title{
Functional Analysis of VPS41-Mediated Neuroprotection in Caenorhabditis elegans and Mammalian Models of Parkinson's Disease
}

\author{
Adam J. Harrington, ${ }^{1}$ Talene A. Yacoubian, ${ }^{2}$ Sunny R. Slone, ${ }^{2}$ Kim A. Caldwell, ${ }^{1,2}$ and Guy A. Caldwell ${ }^{1,2}$ \\ ${ }^{1}$ Department of Biological Sciences, The University of Alabama, Tuscaloosa, Alabama 35487, and 2Departments of Neurology and Neurobiology, Center for \\ Neurodegeneration and Experimental Therapeutics, University of Alabama at Birmingham, Birmingham, Alabama 35294
}

Disruption of the lysosomal system has emerged as a key cellular pathway in the neurotoxicity of $\alpha$-synuclein ( $\alpha$-syn) and the progression of Parkinson's disease (PD). A large-scale RNA interference (RNAi) screen using Caenorhabditis elegans identified VPS-41, a multidomain protein involved in lysosomal protein trafficking, as a modifier of $\alpha$-syn accumulation and dopaminergic neuron degeneration (Hamamichi et al., 2008). Previous studies have shown a conserved neuroprotective function of human VPS41 (hVPS41) against PDrelevant toxins in mammalian cells and C. elegans neurons (Ruan et al., 2010). Here, we report that both the AP-3 (heterotetrameric adaptor protein complex) interaction domain and clathrin heavy-chain repeat domain are required for protecting C. elegans dopaminergic neurons from $\alpha$-syn-induced neurodegeneration, as well as to prevent $\alpha$-syn inclusion formation in an H4 human neuroglioma cell model. Using mutant $C$. elegans and neuron-specific RNAi, we revealed that hVPS41 requires both a functional AP-3 (heterotetrameric adaptor protein complex) and HOPS (homotypic fusion and vacuole protein sorting)-tethering complex to elicit neuroprotection. Interestingly, two nonsynonymous single-nucleotide polymorphisms found within the AP-3 interacting domain of hVPS41 attenuated the neuroprotective property, suggestive of putative susceptibility factors for PD. Furthermore, we observed a decrease in $\alpha$-syn protein level when hVPS41 was overexpressed in human neuroglioma cells. Thus, the neuroprotective capacity of hVPS41 may be a consequence of enhanced clearance of misfolded and aggregated proteins, including toxic $\alpha$-syn species. These data reveal the importance of lysosomal trafficking in maintaining cellular homeostasis in the presence of enhanced $\alpha$-syn expression and toxicity. Our results support hVPS41 as a potential novel therapeutic target for the treatment of synucleinopathies like PD.

\section{Introduction}

Parkinson's disease (PD) is the second most common neurodegenerative disease clinically characterized by the progressive loss of dopaminergic neurons in the substantia nigra and the presence of intracellular protein inclusions termed Lewy bodies. While the etiology of PD is not fully understood, the $\alpha$-synuclein protein ( $\alpha$-syn) is thought to be a central component for the progression of this disease, in that mutations or multiplication of the $\alpha$-syn locus are known genetic causes of autosomal-dominant PD (Polymeropoulos et al., 1997; Singleton et al., 2003). Furthermore, $\alpha$-syn is a polypeptide that can oligomerize to form fibrils and aggregates, and is a primary component in cytoplasmic Lewy

\footnotetext{
Received May 24, 2011; revised Dec. 17, 2011; accepted Dec. 21, 2011

Author contributions: A.J.H., K.A.C., and G.A.C. designed research; A.J.H., S.R.S., and G.A.C. performed research; A.J.H., T.A.Y., and S.R.S. contributed unpublished reagents/analytic tools; A.J.H., T.A.Y., K.A.C., and G.A.C. analyzed data; A.J.H., K.A.C., and G.A.C. wrote the paper.

We thank the Michael J. Fox Foundation for Parkinson's Research, QRxPharma, Ltd., and the Parkinson Association of Alabama for providing funding for this research. We also acknowledge the University of Alabama-University of Alabama at Birmingham Parkinson's Disease Research Discussion Group, and especially Andy West, David Standaert, Shusei Hamamichi, Jenny Schieltz, Max Thompson, Laura Berkowitz, and Kyle Fricke, for contributing to the progress of this project. C. elegans N2 and apb-3(ok429) strains were acquired from the Caenorhabditis Genetics Center. C. elegans strain TU3401 was a kind gift from Marty Chalfie (Columbia University, New York, NY).

Correspondence should be addressed to Dr. Guy A. Caldwell, The University of Alabama, Box 870344, Tuscaloosa, AL 35487. E-mail: gcaldwel@bama.ua.edu.

DOI:10.1523/JNEUROSCI.2606-11.2012

Copyright $\odot 2012$ the authors $\quad 0270-6474 / 12 / 322142-12 \$ 15.00 / 0$
}

bodies (Spillantini et al., 1997). While most cases of PD have no known genetic defect and are thought to involve an environmental component, accumulation of $\alpha$-syn is still observed (Irizarry et al., 1998). Both cellular and animal models also exhibit cellular toxicity through $\alpha$-syn overexpression. With no effective treatment to slow the progression of this disease, the identification of potential therapeutic targets or pathways remains a high priority.

We have previously established Caenorhabditis elegans as a model for age-dependent $\alpha$-syn accumulation and dopaminergic neuron degeneration (Cao et al., 2005; Hamamichi et al., 2008). Importantly, this model has proven predictive in the evaluation of genetic factors and small molecules that protect cells from $\alpha$-syn accumulation and toxicity, with several candidates validated across other organisms, including mammalian systems (Cooper et al., 2006; Gitler et al., 2008, 2009; Su et al., 2010). Using C. elegans assays, Hamamichi et al. (2008) conducted a large-scale RNA interference (RNAi) screen to identify modifiers of $\alpha$-syn pathology. Through this screen, the C. elegans VPS-41 protein was identified as being a top neuroprotective candidate. We subsequently demonstrated that human VPS41 (hVPS41) can also protect dopaminergic neurons from both $\alpha$-syn- and 6-hydroxydopamine (6-OHDA)-induced dopaminergic neurodegeneration in $C$. elegans, as well as protect human SH-SY5Y neuroblastoma cells from PD-relevant neurotoxins, including rotenone and 6-OHDA (Ruan et al., 2010). 
VPS41 is a highly conserved, multidomain protein that functions in lysosomal trafficking of Golgi-derived AP-3 (heterotetrameric adaptor protein complex) vesicles (Radisky et al., 1997; Rehling et al., 1999; Darsow et al., 2001). Given the conserved neuroprotective activity of hVPS41, we conducted a structure/ function analysis of hVPS41 using the nematode model and show that both the AP-3 interaction and clathrin heavy-chain repeat (CHCR) domains are required to protect dopaminergic neurons from $\alpha$-syn-induced degeneration. Through mutant and RNAi analysis, we discerned that both the AP-3 and HOPS (homotypic fusion and vacuole protein sorting) complexes are required for hVPS41-dependent neuroprotection. Interestingly, two human single-nucleotide polymorphisms (SNPs) found within hVPS41 abolish the neuroprotective function of the protein. Our results are further confirmed in a mammalian model of $\alpha$-syn inclusion formation, where protective forms of hVPS41 identified in C. elegans significantly reduce $\alpha$-syn accumulation in human neuroglioma cells. Additionally, expression of hVPS41 reduces the level of overexpressed $\alpha$-syn, suggesting that protein clearance may function in the protective effect of hVPS41. These data provide mechanistic insights into a conserved neuroprotective pathway and support further development of hVPS41 as a prospective therapeutic target for PD.

\section{Materials and Methods}

\section{Plasmid construction}

Human $v p s-41$ cDNA was obtained from Open Biosystems. Truncated hvps41 constructs were generated by using Phusion high-fidelity polymerase (Finnzymes) with primers specified for each truncation available upon request, with fusion of segments and site-directed mutagenesis conducted as previously described (Hobert, 2002). Plasmid entry vectors were generated using Gateway Technology (Invitrogen) to clone PCRamplified constructs into pDONR221 by BP reaction, and the constructs were then further cloned into either Gateway expression vector pDESTDAT-1 (Cao et al., 2005) or pcDNA3.2/V5-DEST (Invitrogen), via LR reaction. Gateway entry vectors were verified by DNA sequencing to validate the constructs. Genomic sid-1 was amplified using Phusion high-fidelity polymerase from genomic DNA isolated from N2 Bristol nematodes and cloned into the pDEST-DAT-1 Gateway expression vector using Gateway Technology, as described above.

\section{C. elegans strains}

Neuroprotection assay. Transgenic C. elegans lines were generated by directly injecting plasmid constructs $\left(\mathrm{P}_{d a t-1}:: \mathrm{Gene} \mathrm{X}\right)$, along with a phenotypic marker $\left[\mathrm{P}_{\text {unc-54 }}::\right.$ mCherry (body wall muscle expression) $]$, into N2 Bristol hermaphrodites to create at least three stable transgenic animals expressing the gene of interest in the dopaminergic neurons as detected by the phenotypic marker mCherry in the body wall muscle cells (Harrington et al., 2011). Transgenic animals expressing mCherry were crossed with isogenic UA44 [baIn11 $\left(\mathrm{P}_{\text {dat }-1}:: \alpha\right.$-syn, $\left.\left.\mathrm{P}_{\text {dat }-1}:: \mathrm{GFP}\right)\right]$ males, and the resulting heterozygous progeny expressing both GFP and mCherry were transferred and allowed to self-fertilize. Homozygous GFP ( $\alpha$-syn)-expressing worms were isolated and used in the dopaminergic neurodegeneration analysis (Table 1 ). AP-3 mutant animals were generated by crossing strain RB662 [apb-3(ok429); provided by the $C$. elegans Gene Knockout Project at Oklahoma Medical Research Foundation (OMRF)] with either strain UA44 or UA126 [baIn11; baEx98 $\left(\mathrm{P}_{\text {dat }-1}:\right.$ hvps41-1, $\mathrm{P}_{\text {unc- } 54:: \mathrm{mCherry})]}$ males to generate strains UA200 [apb-3(ok429); baIn11] and UA194 [apb-3(ok429); baIn11; baEx98], respectively. Homozygous progeny were verified by PCR amplification flanking the $a p b$-3 (ok429) deletion region (Primer 1: $5^{\prime}$-gctcaattgaagtgcactgtg-3'; Primer 2: 5' -ccgagaaatcaacgtcaatcagc- $\left.3^{\prime}\right)$.

Cell-specific RNAi. Transgenic C. elegans lines were generated by directly injecting the expression plasmid $\mathrm{P}_{\text {dat- } 1}:: s i d-1$ along with the phenotypic marker $\mathrm{P}_{m y o-2}:$ :mCherry (pharyngeal expression) (Addgene) into sid-1 (pk3321) hermaphrodites to create stable transgenic animals expressing genomic sid-1 in the dopaminergic neurons as well as the

\section{Table 1. Transgenic C. elegans strains utilized}

\begin{tabular}{|c|c|c|}
\hline Strain & Plasmid construct & Genotype \\
\hline UA44 ${ }^{a}$ & $\alpha$-syn & baln11 $\left[\mathrm{P}_{\text {dat }-1}: \because \alpha\right.$-syn, $\mathrm{P}_{\text {dat }-1: \mathrm{GFP}]}$ \\
\hline UA126 & $\alpha$-syn; VPS41 Isoform 1 & 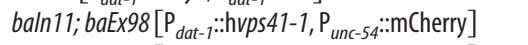 \\
\hline UA128 & $\alpha$-syn; VPS41 Isoform 2 & 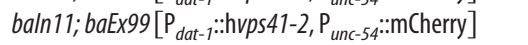 \\
\hline UA177 & $\alpha$-syn; VPS41 A & 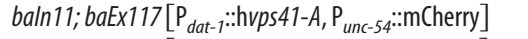 \\
\hline UA179 & $\alpha$-syn; VPS41 B & 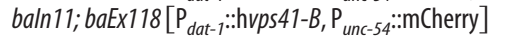 \\
\hline UA181 & $\alpha$-syn; VPS41 C & 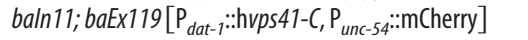 \\
\hline A183 & $\alpha$-syn; VPS41 D & 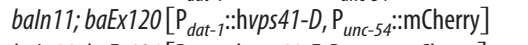 \\
\hline UA185 & $\alpha$-syn; VPS41E & 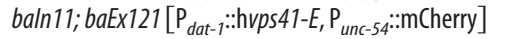 \\
\hline UA187 & $\alpha$-syn; VPS41 F & 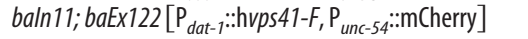 \\
\hline UA189 & $\alpha$-syn; VPS41 G & 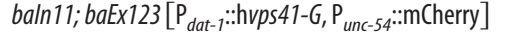 \\
\hline UA191 & $\alpha$-syn; VPS41 T146P & baln11; baEx124 $\left[\mathrm{P}_{\text {dat }-1}:\right.$ hvps $41-T 146 P, \mathrm{P}_{\text {unc-54: }: \text { mCherry }}$ \\
\hline UA193 & $\alpha$-syn; VPS41 A187T & 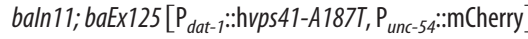 \\
\hline A200 & $\alpha$-syn & $a p b-3(o k 429) ;$ baln11 \\
\hline UA194 & $\alpha$-syn; VPS41 Isoform 1 & $a p b-3(o k 429) ; b a l n 11 ; b a E x 98$ \\
\hline UA195 & genomic sid-1 & sid-1(pk3321); baln33 [ $\mathrm{P}_{\text {dat }-1}::$ sid-1, $\left.\mathrm{P}_{\text {myo-2 }}:: \mathrm{mCherry}\right]$ \\
\hline TU3401 & genomic sid-1 & $\begin{array}{l}\text { sid-1(pk3321); uls69[ }\left[\mathrm{P}_{\text {unc-119::sid-1, p(FJ90 }}\right. \\
\left.\quad\left(\mathrm{P}_{\text {myo-2 }}: \text { :mCherry }\right)\right]\end{array}$ \\
\hline UA196 & $\alpha$-syn; genomic sid-1 & sid-1(pk3321); baln11; baln33 \\
\hline UA197 & $\alpha$-syn; genomic sid-1 & sid-1(pk3321); uls69; baln11 \\
\hline UA49 & $\alpha$-syn::GFP & 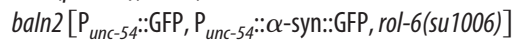 \\
\hline
\end{tabular}

Transgenic C. elegans were generated by microinjecting plasmid constructs into N2 hermaphrodites and crossing into other transgenic or mutant animals (see Materials and Methods). Plasmid constructs expressed in each animal and the resulting genotypes are reported for each strain.

${ }^{a}$ Referenced in Hamamichi et al, 2008; Ruan et al, 2010; Yacoubian et al, 2010.

${ }^{b}$ Referenced in Ruan et al, 2010.

'Gift from Marty Chalfie (Columbia University, New York, NY); Referenced in Calixto et al, 2010.

phenotypic marker (mCherry) in the pharynx. The extrachromosomal array $\left(\mathrm{P}_{\text {dat }-1}:\right.$ :sid- $\left.1, \mathrm{P}_{\text {myo- } 2}:: \mathrm{mCherry}\right)$ was integrated into the C. elegans genome by UV irradiation (Inoue and Thomas, 2000) to create strain

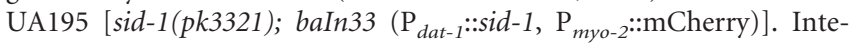
grated transgenic lines were outcrossed with sid-1(pk3321) nematodes five times to remove any extraneous mutations. The isolated homozygous integrated lines were crossed into strain UA44 [baIn11 $\left(\mathrm{P}_{\text {dat }-1}:: \alpha\right.$-syn, $\left.\left.\mathrm{P}_{\text {dat }-1}:: \mathrm{GFP}\right)\right]$ to generate strain UA196 [sid-1(pk3321); baIn11; baIn33], which expresses $\alpha$-syn, GFP, and SID-1 in the dopaminergic neurons and is susceptible to RNAi selectively in these specific neurons.

Worm strain TU3401 [sid-1(pk3321); uIS69 ( $\mathrm{P}_{\text {unc-119::sid-1, pCFJ90 }}$ $\left.\left.\left(\mathrm{P}_{\text {myo-2 }}:: \mathrm{mCherry}\right)\right)\right]$ was generously provided by Marty Chalfie (Columbia University, New York, NY) for pan-neuronal-specific RNAi (Calixto et al., 2010). TU3401 hermaphrodites, which express sid-1 panneuronally, were crossed into strain UA44 to generate strain UA197 [sid1 (pk3321); uIS69; baIn11]; these worms are sensitive to RNAi specifically in the neurons. To isolate homozygous sid-1(pk3321) worms, crossed progeny were grown for three generations in the presence of par-2 (F58B6.3) RNAi, which inhibits embryonic development, allowing for only sid-1(pk3321) worms to develop. After isolating homozygous sid1 (pk3321) animals, worms expressing GFP and mCherry were sequestered and allowed to self-fertilize, and the progeny were examined for isogenic lines.

\section{Dopaminergic neurodegeneration analysis in $\mathrm{C}$. elegans}

C. elegans dopaminergic neurons were analyzed for degeneration as previously described (Hamamichi et al., 2008; Harrington et al., 2011). Briefly, strain UA44 and experimental strains expressing hVPS41 constructs in the dopaminergic neurons were synchronized, grown at $20^{\circ} \mathrm{C}$, and analyzed at specific time points in development, between day 6 and day 10 posthatching (3- and 7-d-old adults), as reported in Results and figure legends, for $\alpha$-syn-induced dopaminergic neurodegeneration. On the day of analysis, the six anterior dopaminergic neurons [four CEP (cephalic) and two ADE (anterior deirid)] were examined in 30 adult hermaphrodite worms, which were immobilized on glass coverslips using $3 \mathrm{~mm}$ levamisole and transferred onto $2 \%$ agarose pads on microscope slides. Worms were considered normal when all six anterior neurons were present without any signs of degeneration, as previously 
reported (Cao et al., 2005; Hamamichi et al., 2008; Ruan et al., 2010; Harrington et al., 2011). In total, at least 90 adult worms were analyzed for each independent truncated hVPS41 transgenic line (30 worms/ trial $\times 3$ independent transgenic lines $\times 3$ trials $=270$ total animals $/$ construct) or RNAi treatment $(30$ worms $/$ trial $\times 4$ trials $=120$ total animals/trial), with the scorer uninformed of the plasmid variant expressed.

\section{RNA isolation and quantitation}

Total RNA was isolated from 50 young adult hermaphrodite worms as previously described (Hamamichi et al., 2008). Briefly, the worms were transferred into $10 \mu \mathrm{l}$ of $10 \%$ Single Worm Lysis Buffer ( $10 \mathrm{~mm}$ Tris, $\mathrm{pH}$ 8.3, $50 \mathrm{~mm} \mathrm{KCl}, 2.5 \mathrm{~mm} \mathrm{MgCl}_{2}, 0.45 \% \mathrm{NP}-40,0.45 \%$ Tween 20, $0.01 \%$ gelatin, $60 \mu \mathrm{g}$ of proteinase $\mathrm{K}$ ) and frozen at $-80^{\circ} \mathrm{C}$ for $1 \mathrm{~h}$. After thawing, $100 \mu \mathrm{l}$ of TRI Reagent (Molecular Research Center) was added to the samples and incubated for $10 \mathrm{~min}$ at room temperature (RT). The samples were freeze thawed five times in liquid $\mathrm{N}_{2}$, vortexed for $15 \mathrm{~s}$ with 10 $\mu \mathrm{l}$ of 1-bromo-3-chloropropane (Acros Organics), incubated for $10 \mathrm{~min}$ at RT, and centrifuged for $15 \mathrm{~min}$ at $14,500 \mathrm{rpm}$ at $4^{\circ} \mathrm{C}$. The supernatant was transferred to an RNase-free tube, mixed with $1.5 \mu$ l of glycoblue (Ambion) and $50 \mu \mathrm{l}$ of $-20^{\circ} \mathrm{C}$ chilled isopropanol, and stored overnight at $-20^{\circ} \mathrm{C}$. After incubation, the sample was centrifuged for $15 \mathrm{~min}$ at $14,500 \mathrm{rpm}$ at $4^{\circ} \mathrm{C}$ and supernatant discarded. The pellet was washed with $100 \mu \mathrm{l}$ of RNase-free ethanol (75\%) and resuspended in $10 \mu \mathrm{l}$ of DEPCtreated water. The sample was treated for 15 min with $1 \mu \mathrm{l}$ of DNase I (Invitrogen) at RT, then for 10 min with $1 \mu \mathrm{l}$ of $25 \mathrm{~mm} \mathrm{EDTA}$ at $65^{\circ} \mathrm{C}$. RT-PCR was performed using SuperScript III RT (Invitrogen) using oligo dT primers following the manufacturers protocols. cDNA amplification was performed using Phusion polymerase (Finnzymes) with primers specified for each construct, available upon request. For each hVPS41 construct, the 5' FLAG primer was used to specifically amplify the transgene. Amplified products were separated on $0.8 \%$ agarose gels and visualized using GelRed staining (Biotium).

For mammalian cells, $30 \mu \mathrm{l}$ of $\mathrm{H} 4$ (human neuroglioma) cells in lysis buffer were transferred to microcentrifuge tubes and frozen at $-80^{\circ} \mathrm{C}$. RNA isolation, RT-PCR, and cDNA amplification were performed as described above.

\section{RNA interference}

RNAi feeding clones (Geneservice) were isolated and grown overnight in LB media with $100 \mu \mathrm{g} / \mathrm{ml}$ ampicillin. NGM plates containing $0.25 \%$ $\beta$-D-lactose were seeded with RNAi feeding clones and allowed to dry. Eight, larval stage 1 (L1) worms (neuron-specific RNAi worm strains, UA196 or UA197) were transferred to the plates and incubated until adulthood at $20^{\circ} \mathrm{C}$. Adult hermaphrodites were transferred to corresponding RNAi plates and allowed to lay eggs for $5 \mathrm{~h}$ to synchronize. The dopaminergic neurons in the F1 progeny of the RNAi-treated worms were analyzed at day 6 and day 8 for degeneration, as described above.

\section{Immunostaining of hVPS41 in H4 cells}

$\mathrm{H} 4$ cells were grown in four-chambered slides and cotransfected with FLAG-hVPS41 variants using Lipofectamine 2000 (Invitrogen) following the manufacturer's protocol. Twenty-four hours post-transfection, cells were fixed with $4 \%$ paraformaldehyde, permeated with $0.5 \%$ Triton $\mathrm{X}-100$ for $20 \mathrm{~min}$ at RT, and immunostained using a primary rabbit monoclonal antibody against FLAG (Sigma) and Alexa Fluor $594 \mathrm{sec}-$ ondary rabbit antibody (Invitrogen). Images were acquired using a Nikon Eclipse E800 epifluorescence microscope equipped with a Texas Red HYQ filter cube (Chroma Technology) and a Cool Snap CCD camera (Photometrics) driven by MetaMorph software (Molecular Devices).

\section{$\alpha-S y n$ inclusion assay}

$\mathrm{H} 4$ cells were grown in four-chambered slides and cotransfected with $\alpha$-syn/truncated green fluorescent protein fusion (synT), synphilin, and either empty vector control or hVPS41 variant using Lipofectamine 2000 (Invitrogen), as previously described (McLean et al., 2001; Yacoubian et al., 2010). Twenty-four hours post-transfection, cells were fixed with $4 \%$ paraformaldehyde, permeated with $0.5 \%$ Triton X-100 for 20 min at RT, and immunostained using a primary $\alpha$-syn antibody (BD Biosciences) and Alexa Fluor 488 secondary antibody (Invitrogen). Every cell with $\alpha$-syn staining ( $>400$ cells/well) was scored as positive or negative for $\alpha$-syn inclusions, with the scorer uninformed of the plasmid variant expressed. Each of the four wells was scored independently with the experiment replicated in triplicate.

\section{Western blotting}

Transfected H4 cells were washed in PBS $24 \mathrm{~h}$ after transfection, collected in lysis buffer [ $150 \mathrm{~mm} \mathrm{NaCl}, 10 \mathrm{~mm}$ Tris-HCl, pH 7.4, 1 mm EGTA, 1 mm EDTA, 2\% SDS, and Halt protease inhibitor cocktail (Thermo Scientific)], sonicated for $10 \mathrm{~s}$ on ice, and centrifuged at $16,000 \times g$ for $10 \mathrm{~min}$. Soluble protein was transferred to a clean tube, and the bicinchoninic acid assay used to quantify protein concentrations. Samples were boiled for $5 \mathrm{~min}$ in $2 \times$ Laemmli sample buffer (Bio-Rad) with $5 \%$ 2-mercaptoethanol, separated on 10\% SDS-polyacrylamide gels (BioRad), and transferred to PVDF membranes (GE Healthcare). Membrane was blocked for $1 \mathrm{~h}$ in 5\% nonfat milk in TBST [ $20 \mathrm{~mm}$ Tris-HCl, pH 7.6, $137 \mathrm{~mm} \mathrm{NaCl}, 0.1 \%$ Tween 20] at RT and incubated with primary mouse monoclonal antibody against $\alpha$-syn (1:5000; Abcam), actin (1:5000; MP Biomedicals), or primary rabbit monoclonal antibody against FLAG (1: 400; Sigma). Blots were washed three times with TBST and incubated with HRP-conjugated mouse or rabbit secondary antibodies $(1: 10,000$; GE Healthcare) for $2 \mathrm{~h}$ at RT. After four washes of $10 \mathrm{~min}$ with TBST, blots were incubated for 5 min with Immobilon Western chemiluminescent HRP substrate (Millipore) and developed using the Fujifilm Image Reader LAS-4000. Multigage software v3.0 (Fujifilm) was used to quantify protein levels.

\section{Imaging and statistics}

Fluorescent microscopy was performed using a Nikon Eclipse E800 epifluorescence microscope equipped with an Endow GFP HYQ filter cube (Chroma Technology). A Cool Snap CCD camera (Photometrics) driven by MetaMorph software (Molecular Devices) was used to acquire deconvolution images. DNA gel and protein blot images were acquired using the Fujifilm Image Reader LAS-4000. Quantification of DNA or protein level was done using Multigage software v3.0 (Fujifilm). The Student's $t$ test was used to statistically analyze all datasets.

\section{Results}

\section{WD40 and clathrin domains of VPS41 are required for protecting $C$. elegans dopaminergic neurons against $\alpha$-syn-induced neurodegeneration in vivo}

Through a large-scale RNAi screen using C. elegans to identify modifiers of $\alpha$-syn pathology, the nematode ortholog of VPS-41 was previously identified as a leading candidate. RNAi knockdown of $C$. elegans $v p s$-41 enhanced $\alpha$-syn aggregation in body wall muscles, while transgenic overexpression of VPS-41 in the dopaminergic neurons protected these neurons against $\alpha$-syninduced neurodegeneration (Hamamichi et al., 2008). Since VPS-41 is a highly conserved metazoan protein (Radisky et al., 1997), we further showed that both human isoforms of VPS41 (hVPS41) were able to protect $C$. elegans dopaminergic neurons from both 6-OHDA-induced and $\alpha$-syn-induced neurodegeneration, validating a preserved function of the VPS41 protein across species (Ruan et al., 2010).

Initially, we sought to determine which functional domains were required for the neuroprotective property of hVPS41 using our $C$. elegans model of $\alpha$-syn-induced dopaminergic neuron degeneration $\left(\mathrm{P}_{\text {dat- } 1}:: \alpha\right.$-syn; $\left.\mathrm{P}_{\text {dat }-1}:: \mathrm{GFP}\right)$ (Fig. 1). Previous studies in yeast identified several functional domains within hVPS41, including AP-3 interaction (WD40), CHCR, RING finger, metal ion binding, and microtubule binding domains (Radisky et al., 1997). To functionally elucidate the minimal domains required for hVPS41-dependent neuroprotection, we created truncated forms of the protein (Fig. $1 B$ ) and generated transgenic animals expressing the truncated proteins specifically in the dopaminergic neurons. These transgenic animals were then crossed into an isogenic worm strain expressing human $\alpha$-syn and GFP in the 

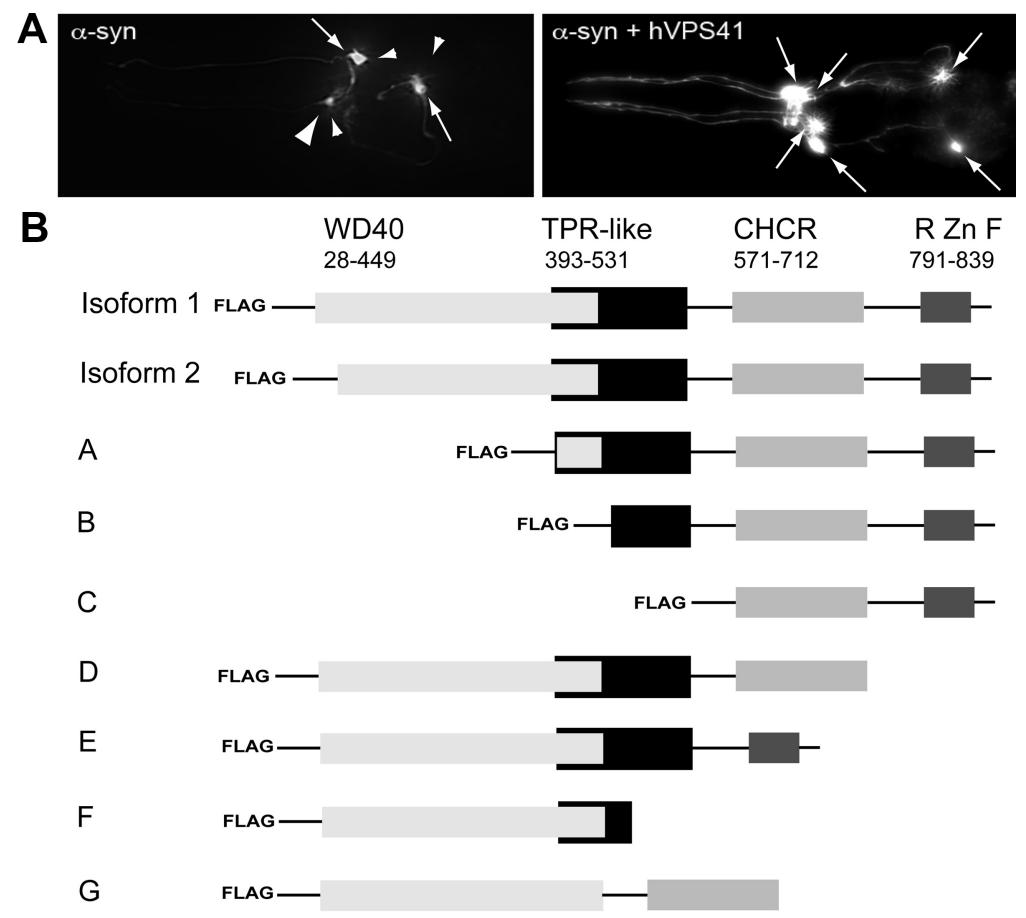

C

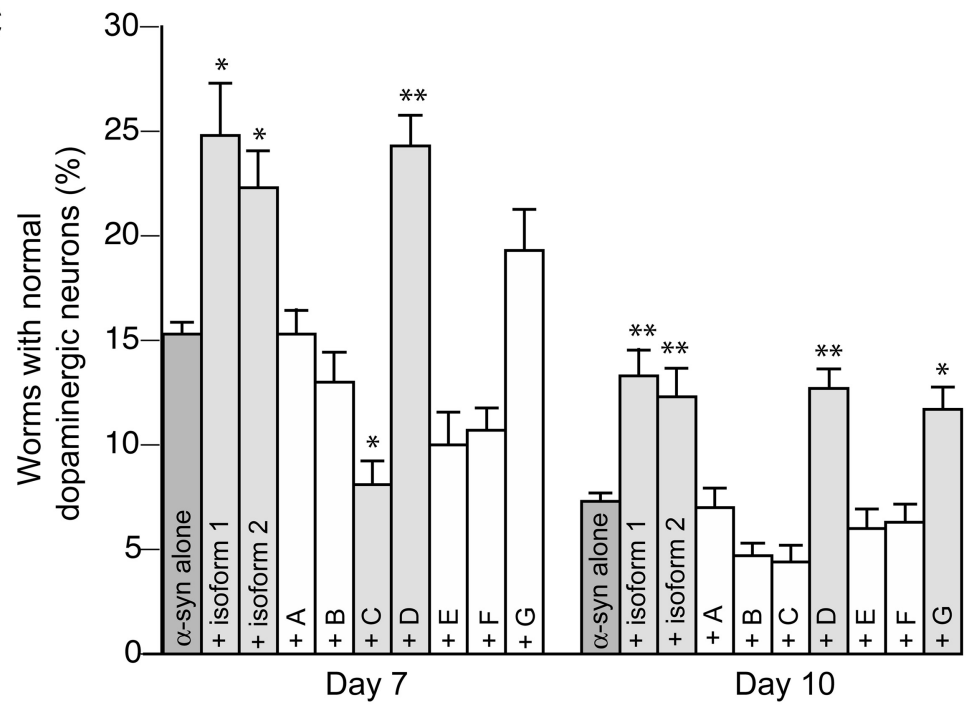

Figure 1. hVPS41 overexpression protects C. elegans dopaminergic neurons from $\alpha$-syn-induced neurodegeneration. $A$, Anterior dopaminergic neurons (4 CEP and $2 \mathrm{ADE}$ ) in worms expressing human $\alpha$-syn and GFP. Left, $A$ worm with only two normal neurons ( 1 CEP and $1 \mathrm{ADE}$ ), where the other four neurons ( 3 CEP and $1 \mathrm{ADE}$ ) have degenerated. Right, The full complement of six anterior dopaminergic neurons of C. elegans expressing hVPS41 Isoform 1 along with $\alpha$-syn and GFP, showing no evidence of degeneration. Arrows show intact dopaminergic neuron cell bodies, large arrowhead shows a degenerating neuron, and small arrowheads indicate regions where neurons have degenerated. $\boldsymbol{B}$, Schematic diagram representing the various truncated hVPS41 protein constructs generated for functional analysis. Predicted functional protein domains were identified using bioinformatics and include the WD40, TPR-like, CHCR, and RING Zn (R Zn F) finger domains. These domains were truncated to determine the minimal regions required for $h V P S 41$ function. The FLAG epitope tag was attached to the $N$ terminus of each truncation. Transgenic animals were generated that express each construct in the DA neurons, and these animals were crossed into the isogenic $\alpha$-syn strain, which displays age-dependent neurodegeneration. C, Overexpression of either full-length hVPS41 or two truncated forms ( $D$ and $G$ ) protects dopaminergic neurons from $\alpha$-syn-induced neurodegeneration. The common domains in all protective forms were the WD40 protein interaction and CHCR domains. Worms were scored as displaying normal dopamine neurons when there was no degeneration observed in the six anterior dopaminergic neurons. Homozygous worms were synchronized and analyzed at days 7 and 10 posthatching. Data are reported as the mean $\pm S D, n=270$ worms. ${ }^{*} p<0.05,{ }^{* *} p<0.01$, Student's $t$ test.

only in the dopaminergic neurons (8 of $\sim 1000$ cells within C. elegans), we were unable to detect the presence of the truncated proteins by Western blotting or immunostaining (data not shown). However, the expression of each hVPS41 construct was verified by RT-PCR using a 5' FLAG primer and a $3^{\prime}$ primer specific for each hVPS41 construct (Fig. $2 A, B$ ).

In quantifying dopaminergic neurodegeneration, worms are considered "normal" when a full complement of all six anterior dopaminergic neurons is present with neuronal processes fully extended to their target areas (Fig. 1A, right). Expression of $\alpha$-syn and GFP results in significant dopaminergic neurodegeneration, whereby only $\sim 15 \%$ of the worm population retains the full complement of normal dopaminergic neurons at $7 \mathrm{~d}$ of development (Fig. 1C). In accordance with previous findings, overexpression of both isoforms of hVPS41 can significantly protect these neurons from degeneration (Fig. 1C). Interestingly, two truncated forms of hVPS41 (truncates D and G) were also able to significantly ameliorate $\alpha$-syn-mediated neurotoxicity (Fig. $1 B, C)$. These two truncated versions of hVPS41 share the AP-3 interaction domain (WD40 repeat) and the CHCR domain. In contrast to prior reports (McVey Ward et al., 2001), the RING-H2 finger does not appear to play a functional role in protecting C. elegans dopaminergic neurons from neurodegeneration, since removal of this domain does not impact the neuroprotective property of hVPS41, as demonstrated by the neuroprotective activity of truncate $\mathrm{D}$. Removal of 107 aa within the tetratricopeptide repeat (TPR)-like domain (truncate G), which separates the WD40 and CHCR domains, also did not alter the overall function of hVPS41 in this assay.

All of the results described thus far have reported the percentage of individual animals within a population $(n \geq 270)$ of worms that exhibit any neuronal degeneration (i.e., if even one of the DA neurons was degenerating, an animal was considered to show neurodegeneration). However, an unequivocal advantage of $C$. elegans is that detailed analyses of individual cells are achievable. Therefore, we also examined the severity of damage within dopaminergic neuron populations. The six dopaminergic neurons within the anterior region were individually scored for degeneration ( $n \geq 1620$ neurons), and statistically identical correlations to what

dopaminergic neurons that exhibit age-dependent neurodegeneration (Fig. 1 $A$, left) (Hamamichi et al., 2008) to determine which truncated forms could rescue $\alpha$-syn-induced neurodegeneration. Due to the limited expression of the hVPS41 constructs was found with animal percentages were also obtained with neuron populations for all hVPS41 constructs examined (data not shown). Together, these data indicate the WD40 protein interaction and CHCR domains are both essential for the conserved 
function of hVPS41 in protecting dopaminergic neurons from $\alpha$-syn-induced neurodegeneration in vivo.

\section{VPS41 requires both AP-3 and HOPS complexes for neuroprotection}

Previous studies in yeast have identified at least two independent pathways that regulate protein sorting and trafficking from the Golgi to the vacuole/lysosome, with VPS-41 functioning within one of these, the alkaline phosphatase (ALP) pathway (Darsow et al., 2001). Protein trafficking through the ALP pathway requires the AP-3 and transports cargo directly to the vacuole by bypassing early, sorting endosomes. The N-terminal WD40 domain of VPS-41 directly interacts with the large $\delta$-subunit of the AP-3 complex, while the C-terminal CHCR domain of VPS-41 can homo-oligomerize to form a clathrin-like outer shell surrounding the AP-3 vesicle (Rehling et al., 1999; Darsow et al., 2001). As the vesicles approach the vacuole, VPS-41 functions as part of the HOPS docking complex along with VPS-39 to promote vacuole fusion, through activation of the Rab GTPase RAB-7 (Brett et al., 2008; Cabrera et al., 2009).

To determine whether hVPS41 is functioning to protect dopaminergic neurons from $\alpha$-syn-induced degeneration via lysosomal trafficking of AP-3 transport vesicles, we used the availability of a C. elegans AP-3 complex mutant, $a p b$ 3(ok429), which is a predicted null mutation that has defects in lysosome-related gut granule formation (Hermann et al., 2005). Our isogenic line of worms expressing $\alpha$-syn, GFP, and hVPS41 in the dopaminergic neurons was crossed into $a p b$-3(ok429) mutant worms, and the dopaminergic neurons were analyzed for the level of degeneration at days 7 and 10 (Fig. $3 A$ ). While overexpression of hVPS41 was significantly able to protect worms from dopaminergic neurodegeneration in a wild-type (N2) background, hVPS41 was unable to elicit the neuroprotective effect in the absence of a functional AP-3 complex, as observed in the $a p b$-3(ok429) mutant background (Fig. $3 A$ ). This same correlation was obtained when comparing total individual neurons across animals (data not shown), instead of worm populations (Fig. 3A).

To further validate the functional requirement of the AP-3 and HOPS complex, we took advantage of a recently reported innovation enabling us to conduct neuron-specific RNAi by generating a worm strain that overexpresses the dsRNA transporter SID-1 specifically in the dopaminergic neurons. Since C. elegans neurons are known to be highly resistant to RNAi, possibly through low expression of SID-1, Calixto et al. (2010) created a strain expressing genomic sid-1 under the pan-neuronal promoter $\left(\mathrm{P}_{\text {unc-119 }}\right)$ in a sid-1(pk3321) mutant background; this strain allowed for neuron-specific gene knockdown in worms, with all other tissues/cells being resistant. Using a similar approach, we created a sid-1 (pk3321) mutant strain of C. elegans that expresses wild-type SID-1 specifically in the dopaminergic neurons under control of the dopamine transporter promoter $\left(\mathrm{P}_{\text {dat-1 }}\right)$, thereby enabling dopaminergic neuron-specific RNAi. The dopaminergic neuron-specific RNAi strain was crossed into our isogenic UA44 $\left(\mathrm{P}_{\text {dat }-1}:: \alpha\right.$-syn; $\left.\mathrm{P}_{\text {dat }-1}:: \mathrm{GFP}\right)$ strain to examine the effect of neuronal gene knockdown to identify modifiers of $\alpha$-syn toxicity selectively in dopaminergic neurons. With the expression of this additional transgene $\left(\mathrm{P}_{\text {dat }-1}::\right.$ sid-1), we observed slightly less dopaminergic neurodegeneration, yet this was still significant compared with worms not expressing $\alpha$-syn and GFP $\left(\mathrm{P}_{\text {dat }-1}:: \alpha\right.$-syn; $\left.\mathrm{P}_{\text {dat }-1}:: \mathrm{GFP}\right)$.

Interestingly, knockdown of either of the HOPS complex components, VPS-39 and VPS-41 or the VPS-41-interacting $\delta$-subunit of the AP-3 complex (APD-3), significantly enhanced the level of dopaminergic neurodegeneration elicited through 

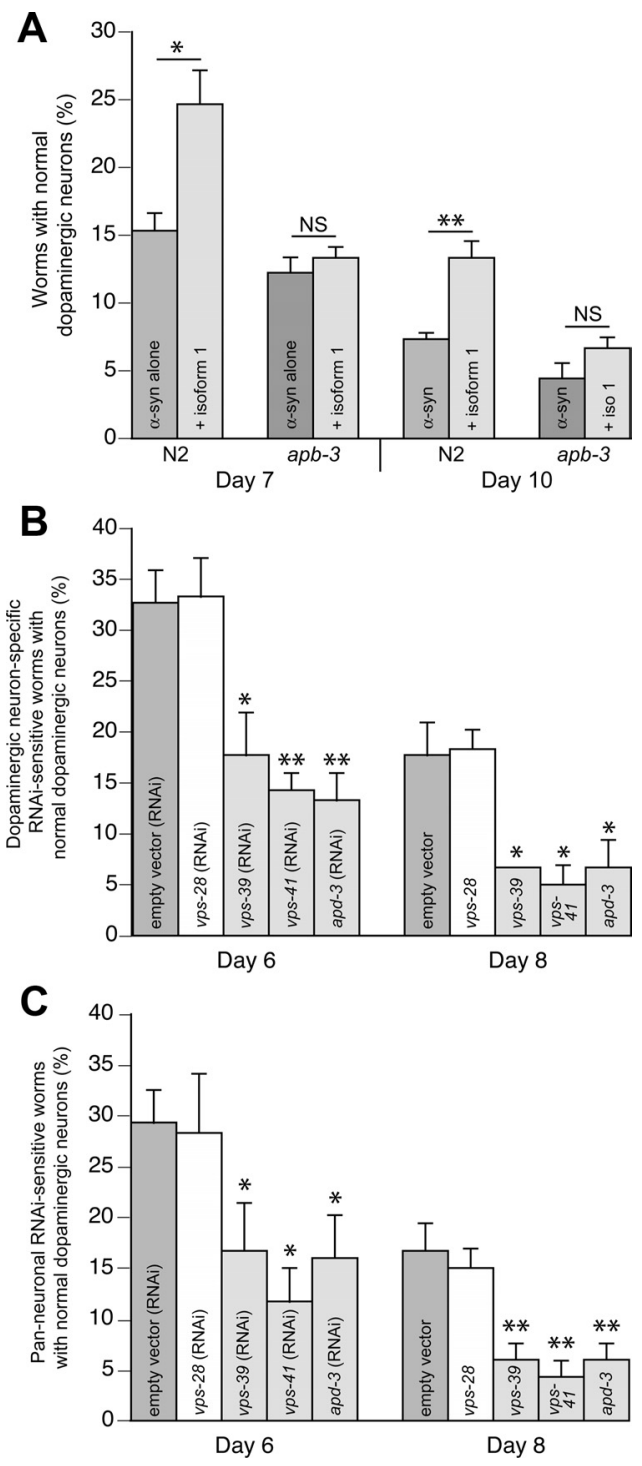

Figure 3. hVPS41 requires both a functional AP-3 and HOPS complex to protect dopaminergic neurons from $\alpha$-syn-induced neurodegeneration. $A$, Worms expressing $\alpha$-syn and GFP with or without hVPS41 expression were crossed into apb-3(ok429) mutant animals. Resulting homozygous animals were synchronized and analyzed at days 7 and 10 posthatching. Overexpression of hVPS41 protected dopaminergic neurons from degeneration in a wild-type (N2) background but failed to protect neurons from $\alpha$-syn toxicity in an AP-3 complex mutant (apb-3). Data are reported as the mean \pm SD, $n=270$ worms. ${ }^{*} p<0.05,{ }^{* *} p<0.005$, Student's $t$ test. $B$, C, RNAi knockdown of components within the HOPS (VPS-39 and VPS-41) or AP-3 complex (APD-3) specifically in the dopaminergic neurons $(\boldsymbol{B})\left\{\mathbb{P}_{\text {dat }-1:: s i d-1}\right.$ in sid-1 mutant $[$ sid-1(pk3321)]\} or pan-neuronally $(\boldsymbol{C})$

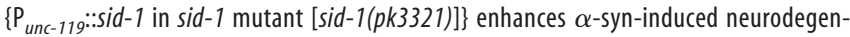
eration in worms not overexpressing hVPS41. The F1 progeny of worms exposed to RNAi feeding bacteria were synchronized, and the dopamine neurons were analyzed for degeneration at days 6 and 8 posthatching. RNAi bacteria that do not express an RNAi clone (empty) or the VPS-28 RNAi clone were used as negative controls. Data are reported as the mean $\pm S D, n=120$ worms. ${ }^{*} p<0.05,{ }^{* *} p<0.005$, Student's $t$ test.

$\alpha$-syn overexpression in the dopaminergic neuron-specific RNAi strain (Fig. 3B). Knockdown of $v p s$-28 did not enhance $\alpha$-syninduced neurodegeneration. Since the VPS-28 gene product encodes ESCRT-1 (endosomal sorting complex required for transport), and it is not involved in Golgi-to-lysosomal trafficking, but is required for cell surface receptor degradation, we chose this as a negative control. Dopaminergic neuron-specific RNAi data were confirmed using a pan-neuronal RNAi strain (Calixto et al., 2010) (Fig. 3C), thus verifying that the dopaminergic RNAi strain did not alter the expression levels of proteins due to promoter saturation. All data obtained comparing worm populations (Fig. $3 B, C$ ) once again correlated with individual neuron data (data not shown). Additionally, RNAi knockdown of VPS39 , VPS-41, APD-3, or APB-3 in the absence of $\alpha$-syn does not cause the dopaminergic neurons to degenerate, indicating that these genes play a role in protecting neurons from $\alpha$-syn neurotoxicity (data not shown). Together, these data reveal the functional relevance of the AP-3 and HOPS complex in impacting $\alpha$-syn-induced neurodegeneration as well as validate the requirement of a functional AP-3 complex for hVPS41 to function.

\section{SNPs in VPS41 alter neuroprotective function}

With advances in genomic sequencing, genetic variance within populations is an emerging field of intense interest, with identification of SNPs in specific genes being associated with human diseases. Several SNPs have been directly associated with the occurrence of PD, including mutations in the gene encoding $\alpha$-syn (A30P and A53T). However, these mutations only account for a small population of patients with this disease, indicating that further genetic or environmental factors may play pivotal roles in the onset and progression of PD. Since we have shown the functional requirement of hVPS41 in protecting dopaminergic neurons from degeneration due to $\alpha$-syn overexpression, we evaluated several SNP databases, including the NCBI SNP database (www.ncbi.nlm.nih.gov/snp), GeneCards (www.genecards. org), and SNPs3D (www.snps3d.org), where several SNPs have been identified within the general human population. Interestingly, the domain in which hVPS41 interacts with the AP-3 complex (WD40 domain) has several SNPs (T146P and A187T) reported within it that are predicted to be deleterious to the structure/function of the protein (Fig. 4A) (SNPs3D). These SNPs change functional groups of amino acids; there is a hydrophilicto-hydrophobic amino acid change in the T146P SNP, while A187T changes this residue from hydrophobic to hydrophilic. In both cases, the structure and/or function of the WD40 domain could be altered. Moreover, both SNPs have a minor allelic frequency of $f=0.02(2 \%)$, indicating that a small percentage of the population contains either of these SNPs.

Since these SNPs have not been functionally analyzed and are predicted to be deleterious to the activity of the protein (SNPs3D), we introduced these changes into hVPS41 and overexpressed the SNP mutants in the dopaminergic neurons to investigate their impact in our worm model of $\alpha$-syn-induced neurodegeneration. The hVPS41 SNP transgenes were verified as being transcribed within the $\alpha$-syn-expressing worms by RTPCR (Fig. 2B). Strikingly, overexpression of hVPS41 T146P or A187T abrogated the dopaminergic neuroprotection provided by wild-type hVPS41 against $\alpha$-syn-induced neurodegeneration (Fig. 4B). Data comparing worm populations (Fig. 4B) corroborated with collective individual neuron data (data not shown). While yet to be associated with human PD patient genomes, these data indicate that the T146P or A187T variants in the WD40 domain alter the neuroprotective property of hVPS41 in an in vivo animal model of $\mathrm{PD}$.

\section{hVPS41 constructs are localized within the cytoplasm of}

H4 cells

The neuroprotective capacity of the specific hVPS41 constructs may be due to those specific forms being expressed as proteins, while the truncated and SNP proteins may not be expressed, due to misfolding and/or degradation of the polypeptide. To ac- 

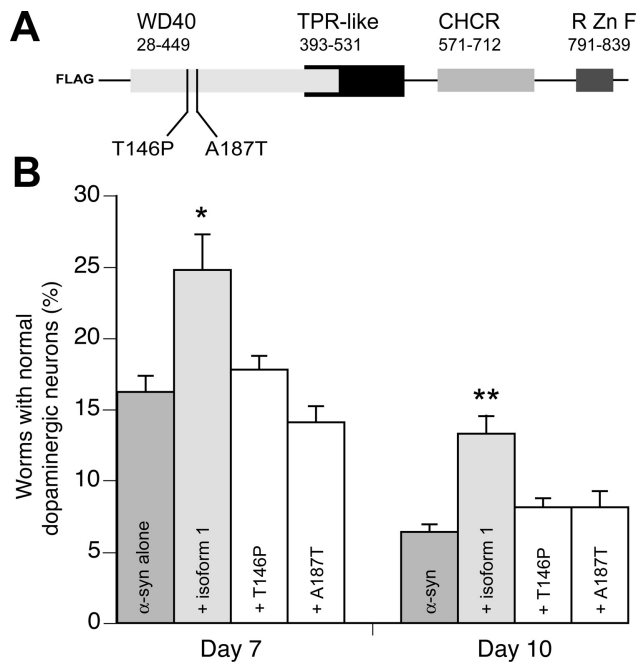

Figure 4. Two SNPs found within the WD40 domain of hVPS41 alter the neuroprotective property afforded against $\alpha$-syn toxicity. $\boldsymbol{A}$, Schematic diagram showing the location and amino acid changes associated with two SNPs within hVPS41. Both SNPs are located within the WD40 protein interaction domain, which is required for hVPS41-mediated neuroprotection in worms (Fig. 1C); the WD40 domain directly interacts with the $\delta$-subunit of the AP-3 complex in yeast. Both SNPs have been reported to be present in a small percentage of the general human population and are predicted to be deleterious to the structure/function of the protein (www.snps3d.org). $\boldsymbol{B}, 0$ verexpression of hVPS41 with either SNP T146P or A187T failed to protect DA neurons from $\alpha$-syn-induced neurodegeneration. Transgenic animals expressing either wild-type or mutant hVPS41 were crossed into isogenic $\alpha$-syn worms. Homozygous worms were synchronized and analyzed at days 7 and 10 posthatching. Data are reported as the mean $\pm S D, n=270$ worms. ${ }^{*} p<0.05,{ }^{* *} p<0.005$, Student's $t$ test.

cess the expression pattern of the various hVPS41 construct proteins, human neuroglioma $(\mathrm{H} 4)$ cells were transfected with FLAG-hVPS41 constructs, and transfected cells were fixed and immunostained using a FLAG-specific antibody (Sigma) $24 \mathrm{~h}$ post-transfection. The intracellular localization of both hVPS41 isoforms showed diffuse expression of hVPS41 protein within the cytoplasm and perinuclear region of $\mathrm{H} 4$ cells, as detected by FLAG antibody staining (Fig. 5A). Most hVPS41 truncates (except truncate F) and both hVPS41 SNPs were localized in a similar manner and expression level when compared with hVPS41 isoforms 1 and 2, indicating that the truncated proteins can be expressed (Fig. 5A). Truncated hVPS41 construct F may not express a stable protein due to the substantially reduced size of the polypeptide encoded, which may be misfolded and degraded. hVPS41 truncate $\mathrm{F}$ also mimics the $C$. elegans vps41(ep402) mutant allele, which is embryonic-lethal to the organism in the homozygous state and exhibits an increase in germline apoptosis (Lackner et al., 2005), suggesting that this truncated protein is defective in function. Additionally, most hVPS41 truncates (except B and F) and both hVPS41 SNPs were detected through Western blot analyses using FLAG antibody staining, with proteins detected at their predicted molecular weight (Fig. $5 B, C$ ). While immunostaining of transfected $\mathrm{H} 4$ cells detected hVPS41 truncate B, this truncated protein was not detected through Western blot analysis, possibly due to the instability of this protein. In agreement with immunostaining results, hVPS41 truncate F was not detected either, further supporting the lack of expression of this truncated protein. These results show that the protective hVPS41 isoforms and hVPS41 truncates, $\mathrm{D}$ and $\mathrm{G}$, are expressed as proteins, while the nonprotective hVPS41 truncates A-C and E, and both hVPS41 SNPs are also able to express proteins.

\section{VPS41 reduces cytoplasmic $\alpha$-syn inclusion formation in vitro}

A key pathological feature of PD is the formation of cytoplasmic protein inclusions, containing $\alpha$-syn, which are thought to underlie the cellular toxicity and promote neuronal cell death. To further validate the results obtained in our evaluation of hVPS4 1 using C. elegans, we used a human cell culture model of $\alpha$-syn inclusion body formation (McLean et al., 2001). Cotransfection of $\mathrm{H} 4$ cells with an $\alpha$-syn/truncated green fluorescent protein fusion (synT) and synphilin results in the formation of cytoplasmic inclusions in $\sim 50 \%$ of cells that immunostained for $\alpha$-syn (Fig. 6A,B). Using this model, we cotransfected $\mathrm{H} 4$ cells with either an empty vector or an hVPS41 construct, and $24 \mathrm{~h}$ after transfection we fixed and immunostained the cells using an $\alpha$-syn-specific antibody. Interestingly, both isoforms of hVPS41, as well as the two truncated forms (D and G) that reduced neurodegeneration in C. elegans, also significantly decreased the number of inclusion-positive cells by $\sim 40 \%$ in $\mathrm{H} 4$ cells (Fig. $6 A, B)$. Truncate $B$, which did not protect $C$. elegans dopaminergic neurons from $\alpha$-syn toxicity, was also unable to alter the degree of $\alpha$-syn inclusion formation in $\mathrm{H} 4$ cells (Fig. $6 B$ ). Additional correlative results between $C$. elegans and $\mathrm{H} 4$ cells were obtained when the hVPS41 T146P and A187T SNPs were examined. Similar to the lack of effect of these variants seen in $C$. elegans, the number of inclusion-positive $\mathrm{H} 4$ cells when transfected with either variant was similar to the empty vector control (Fig. $6 \mathrm{~B}$ ). The intracellular localization of hVPS41 was detected diffusely expressed within the cytoplasm and perinuclear region of $\mathrm{H} 4$ cells using FLAG immunostaining (Fig. $6 \mathrm{C}$ ). These data confirm the $C$. elegans results in identifying functional domains and SNPs within hVPS41, which may alter cellular homeostasis in the presence of increased $\alpha$-syn protein expression.

\section{VPS41 promotes the clearance of $\alpha$-syn in human neuroglioma cells}

Defects with lysosomal function in protein clearance are proposed to contribute to the progression of $\mathrm{PD}$, with the $\alpha$-syn protein being degraded, in part, though autophagy (Shin et al., 2005). Since $\alpha$-syn accumulation may be associated with the neurotoxicity of dopaminergic neurons, we wanted to determine whether hVPS41 could promote the clearance of $\alpha$-syn under conditions of increased expression in human neuroglioma cells. We previously reported that hVPS41 overexpression could prevent the increase in Triton-insoluble (oligomeric) $\alpha$-syn species in human neuroblastoma (SH-SY5Y) cells after rotenone treatment (Ruan et al., 2010), and here we report the ability of hVPS41 to decrease the number of cells with $\alpha$-syn-positive cytoplasmic inclusions in $\mathrm{H} 4$ cells (Fig. 6). Using the $\mathrm{H} 4$ cell model of $\alpha$-syn inclusion formation described above, we isolated total protein from cells after transfection with synT, synphilin, and either an empty vector control or hVPS41, and quantified the levels of synT protein expressed. While a high level of synT was observed in the control cells, a significant reduction $(\sim 50 \%)$ in synT was recorded when hVPS41 was also expressed (Fig. $7 A, D$ ); this reduction was not due to transcriptional regulation of the transgenes (Fig. 7B). In accordance with our synT inclusion formation results (Fig. 6B), we demonstrate that SNPs (T146P and A187T) found within the WD40 domain of hVPS41 prevent the protein from reducing the level of synT protein, while both wild-type hVPS41 isoforms significantly reduced the synT protein level (Fig. 7C,D). These data confirm that when either SNP is present in hVPS41, the function of hVPS41 is altered, preventing the protein from reducing $\alpha$-syn accumulation. Thus, these specific 

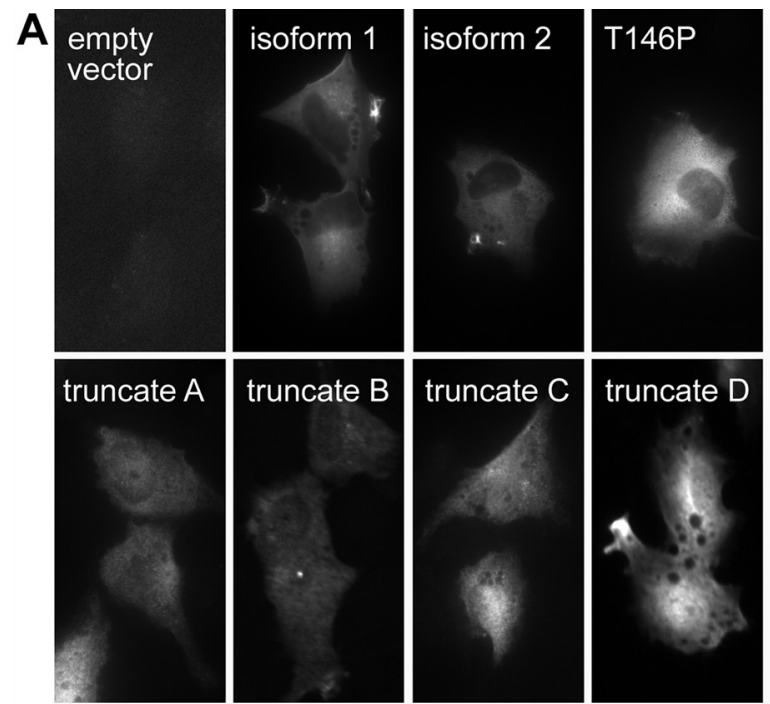

B
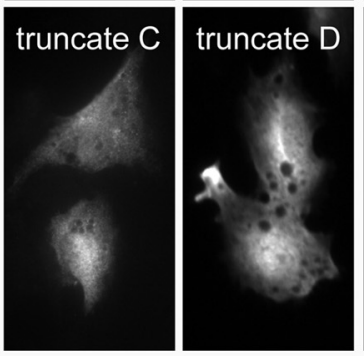

C

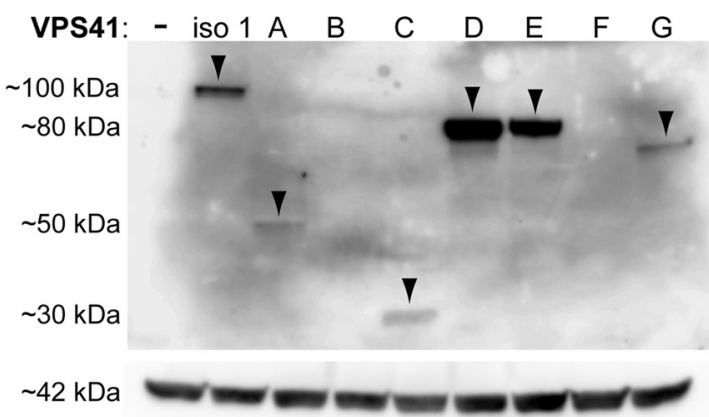

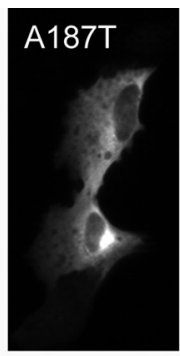
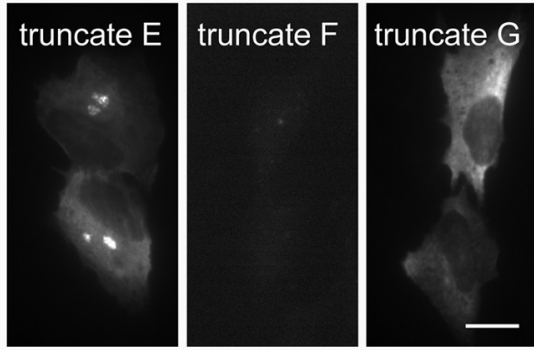

- iso 1 iso 2 T146P A187T
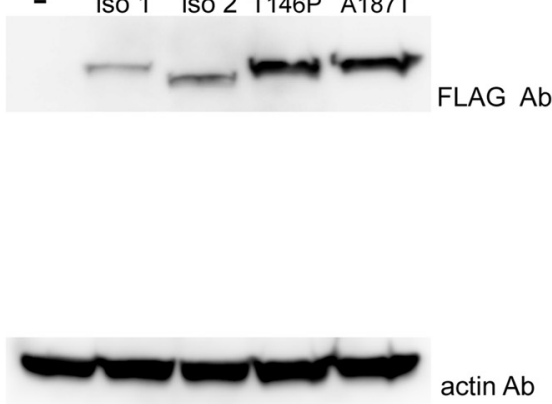

Figure 5. Expression of hVPS41 constructs in H4 cells. A, Immunostaining of transfected H4 neuroglioma cells using a FLAG-specific primary antibody with an Alexa Fluor 594conjugated secondary antibody detects FLAG-hVPS41 protein diffusely in the cytoplasm and perinuclear region. Both human isoforms, the SNPs, and most of the truncates displayed similar expression patterns, except for truncate $F$, which was not expressed. The reduced size of hVPS41 truncate $F$ may result in misfolding and degradation of this smaller protein. Scale bar, $20 \mu \mathrm{m} . \boldsymbol{B}, \boldsymbol{C}$, Western blot showing expression of hVPS41 constructs in H4 cell lysates. H4 neuroglioma cells were transfected with hVPS41 constructs, and total protein was isolated $24 \mathrm{~h}$ after transfection. Proteins were resolved using SDS-PAGE and transferred to PVDF membranes. B, Using a FLAG-specific antibody, full-length hVPS41 was detected at $\sim 102 \mathrm{kDa}$ in transfected cells. Proteins for truncated hVPS41 A ( $\sim 48 \mathrm{kDa}), C(\sim 34 \mathrm{kDa}), \mathrm{D}(\sim 82 \mathrm{kDa}), \mathrm{E}(\sim 82 \mathrm{kDa})$, and G ( $\sim 70 \mathrm{kDa})$ (arrowheads) were also detected using FLAG antibody staining. Truncated proteins for hVPS41 B and F were not detected through Western blot analysis, possibly due to instability of these proteins. Actin ( $~ 42 \mathrm{kDa})$ was used for a loading control. C, Both hVPS41 isoforms and hVPS41 SNPs were detected with a FLAG-specific antibody. hVPS41 isoform 2 is missing 25 aa compared with hVPS41 isoform 1, resulting in a protein of reduced size ( $\sim 100 \mathrm{kDa}$ ). Both hVPS41 SNPs introduced into full-length isoform 1 were detected at $\sim 102 \mathrm{kDa}$, similar to hVPS41 isoform 1 . Actin $(\sim 42 \mathrm{kDa})$ was used for a loading control.

polymorphisms, or other currently unidentified but functionally equivalent SNPs in hVPS41, may represent putative susceptibility factors for Parkinson's disease.

\section{Discussion}

Increasing evidence supports a role for dysfunctional lysosomal trafficking and protein degradation as underlying the pathology of PD. Deleterious cellular consequences arising from lysosomal dysfunction have been proposed to underlie the age-related progression of the disease (Chu and Kordower, 2007). Lysosomal targeting of misfolded and aggregated proteins for degradation, including $\alpha$-syn, has been shown to be largely mediated by macroautophagy and chaperone-mediated autophagy (CMA) (Webb et al., 2003; Cuervo et al., 2004). Mutations in $\alpha$-syn that are associated with autosomal-dominant forms of PD have been shown to block CMA (Cuervo et al., 2004), and overexpression of wild-type $\alpha$-syn impairs macroautophagy (Winslow et al., 2010). Accumulation of $\alpha$-syn is observed within Lewy bodies in postmortem PD brains (Spillantini et al., 1997). While the precise form of $\alpha$-syn aggregates comprising the toxic species in vivo remains unresolved, enhanced $\alpha$-syn expression has been conclusively associated with neurotoxicity and PD (Singleton et al., 2003). In C. elegans, transgenic overexpression of $\alpha$-syn leads to age-dependent $\alpha$-syn accumulation and dopaminergic neuron degeneration (Lakso et al., 2003; Cao et al., 2005; Kuwahara et al., 2006; Hamamichi et al., 2008; van Ham et al., 2008; Karpinar et al., 2009). Depletion of the E1-like enzyme required for the initiation of autophagosome formation, atg-7, results in neurodegeneration in mice (Komatsu et al., 2006) as well as enhanced $\alpha$-syn accumulation in C. elegans (Hamamichi et al., 2008). Augmentation of a lysosomal enzyme, cathepsin D, promotes $\alpha$-syn clearance in vitro and protects $C$. elegans dopaminergic neurons from $\alpha$-syn toxicity (Qiao et al., 2008). Furthermore, two PARK genes, PARK9 and PARK16, have been identified that function in the lysosomal system. Mutations in the lysosomal P-type ATPase, ATP13A2 (PARK9), have been linked to inherited PD (Ramirez et al., 2006). Genetic knockdown of the C. elegans homolog of ATP13A2, catp-6, enhances $\alpha$-syn misfolding and accumulation, while transgenic overexpression of catp-6 in worm dopaminergic 

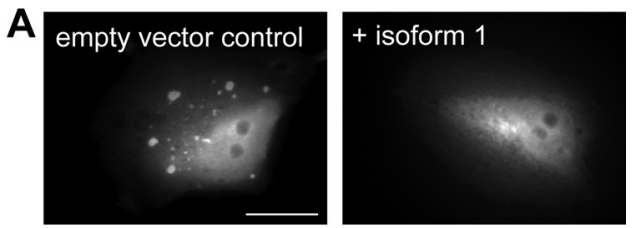

B

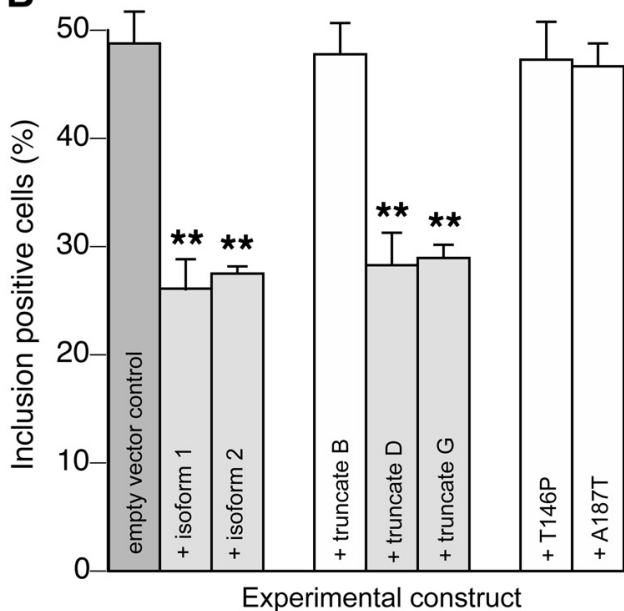

C

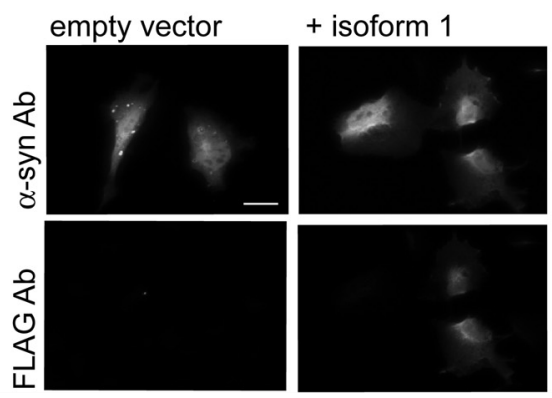

Figure 6. Overexpression of hVPS41 in human neuroglioma cells reduces the number of $\alpha$-syn inclusion-positive cells. $\boldsymbol{A}, \boldsymbol{B}$, Cotransfection of $\mathrm{H} 4$ cells with synT, synphilin, and an empty vector control results in formation of cytoplasmic puncta $(\boldsymbol{A}$, left) that immunostain positive for $\alpha$-syn in $\sim 50 \%$ of transfected cells $(\boldsymbol{B})$. Cells were fixed and immunostained $24 \mathrm{~h}$ post-transfection. Cotransfection of either isoform of hVPS41 or the two truncated constructs that were protective in C. elegans dopaminergic neurons (truncates $D$ and $G$ ) significantly reduced the number of $\alpha$-syn inclusion-positive cells ( $\boldsymbol{A}$, right), while control truncate $B$ did not reduce the number of positive cells. When either SNP reported within the WD40 domain of hVPS41 (T146P or A187T) is present, hVPS41 is no longer able to reduce inclusion formation. Cells stained for $\alpha$-syn were scored as either positive $(\boldsymbol{A}$, left) or negative ( $\boldsymbol{A}$, right) for $\alpha$-syn cytoplasmic inclusions, with the rater blind to each experimental condition. Each experimental condition was repeated three times with four replicas per experiment. Data are reported as the mean \pm SD. ${ }^{* *} p<0.001$, Student's $t$ test. Scale bar, $20 \mu \mathrm{m}$. C, H4 cells transfected with synT, synphilin, and either empty vector control (left panels) or FLAG-hVPS41 isoform 1 (right panels) were immunostained using a primary mouse monoclonal antibody against $\alpha$-syn with an Alexa Fluor 488-conjugated goat anti-mouse secondary antibody (top panels) or a primary rabbit monoclonal antibody against FLAG with an Alexa Fluor 594-conjugated goat anti-rabbit secondary antibody (bottom panels). hVPS41 is expressed in cells cotransfected with synT and is diffusely localized within the cytoplasm and perinuclear region. Expression of hVPS41 reduces the number of $\alpha$-syn inclusion-positive cells. Scale bar, $20 \mu \mathrm{m}$.

neurons ameliorated $\alpha$-syn-induced neurodegeneration (Gitler et al., 2009).

Recent identification of the PARK16 locus revealed a novel RAB7L1 mutation as being associated with PD (Simón-Sánchez et al., 2009; Tucci et al., 2010). RAB7 is a member of the Rab GTPase superfamily involved in vesicle trafficking and functions at the lysosome to promote vesicle tethering and fusion. Interest- ingly, in yeast, RAB7 is activated by the HOPS complex component VPS39, which functions as a guanine nucleotide exchange factor, and activated RAB7 directly interacts with VPS41 in the HOPS complex to promote vesicle tethering and subsequent lysosomal fusion (Brett et al., 2008). Depletion of the Drosophila VPS41 homolog, Light, impairs lysosomal acidification and protein degradation (Swetha et al., 2011). Here, we show that overexpression of hVPS41 in human neuroglioma cells is able to reduce the number of $\alpha$-syn inclusion-positive cells and decrease the level of $\alpha$-syn protein, possibly through enhanced lysosomal trafficking of $\alpha$-syn. Therefore, the significance of these data is further supported by identification of RAB7L1 as a potential genetic cause of PD.

Additional evidence supporting the role of $\alpha$-syn impairment of protein trafficking has been previously reported. In yeast, overexpression of $\alpha$-syn leads to profound defects in ER-Golgi trafficking that can be rescued through expressing of the Rab GTPase RAB1, which functions in the tethering and docking of ER transport vesicles to the Golgi (Cooper et al., 2006). Further analysis in mammalian and C. elegans neurons revealed two other Rab proteins, RAB3A and RAB8A, which can function to protect cells against $\alpha$-syn toxicity (Gitler et al., 2008). RAB3 functions in docking and tethering of neurotransmitter vesicles at the presynaptic terminal specifically in neurons, while RAB8 functions in post-Golgi trafficking. With VPS41 being involved in Golgi-lysosome protein transport, our data support the involvement of post-Golgi trafficking in mediating $\alpha$-syn toxicity. Together, impaired protein trafficking throughout the cell may underlie the toxicity induced through increased $\alpha$-syn expression, and by promoting protein transport machinery, cells are able to overcome this proteostatic imbalance.

Structural analysis of hVPS41 revealed that both the WD40 protein interaction and CHCR domains are required for hVPS41 to protect against neurotoxicity (Fig. 1). In contrast to previous studies (McVey Ward et al., 2001), truncation of the RING-H2 domain did not alter the neuroprotective function of hVPS41 in our assays, indicating that this domain is dispensable for hVPS41-mediated neuroprotection. These structure/function data were further corroborated using a human cell culture model of $\alpha$-syn inclusion formation, where both the WD40 and CHCR domain were required for hVPS41 to reduce the number of $\alpha$-syn inclusion-positive $\mathrm{H} 4$ cells (Fig. 6). In yeast, the WD40 domain of VPS41 has been shown to directly interact with AP- $3 \delta$-adaptin subunit to facilitate protein trafficking between the late Golgi and vacuolar lysosome (Rehling et al., 1999), while the CHCR domain directs homo-oligomerization of VPS41 to form a clathrinlike lattice surrounding vesicles being trafficked to the vacuole (Darsow et al., 2001). As the vesicle approaches the vacuole, the HOPS docking complex, composed of VPS39 and VPS41, are recruited to the vesicle and function in vacuole fusion through activation of the yeast RAB7 homolog by VPS39 (Brett et al., 2008). Identification of the AP-3 interacting domain as being a required structural motif for hVPS41 function led us determine whether the AP-3 complex was required for the neuroprotective property of hVPS41. With only one C. elegans AP-3 complex mutant strain available, we generated worms expressing $\alpha$-syn with or without hVPS41 in the dopaminergic neurons and showed that mutations in the AP-3 $\beta$-subunit $(a p b-3)$ attenuated the neuroprotective effect of hVPS41. Without worm mutants in the AP-3 $\delta$-subunit or HOPS complex, we used a novel methodology to conduct cell-specific RNAi through expression of the dsRNA transporter (SID-1), either in all neurons (Calixto et al., 2010) or specifically in the dopaminergic neurons, within the 
A

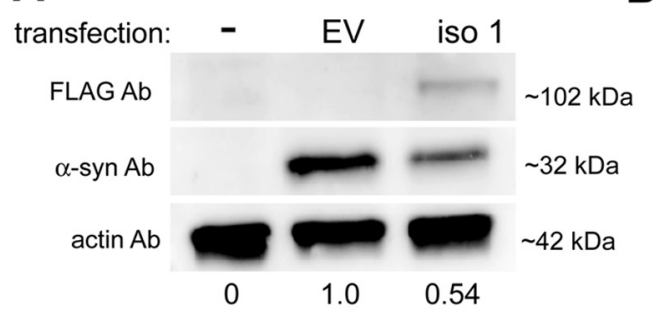

C
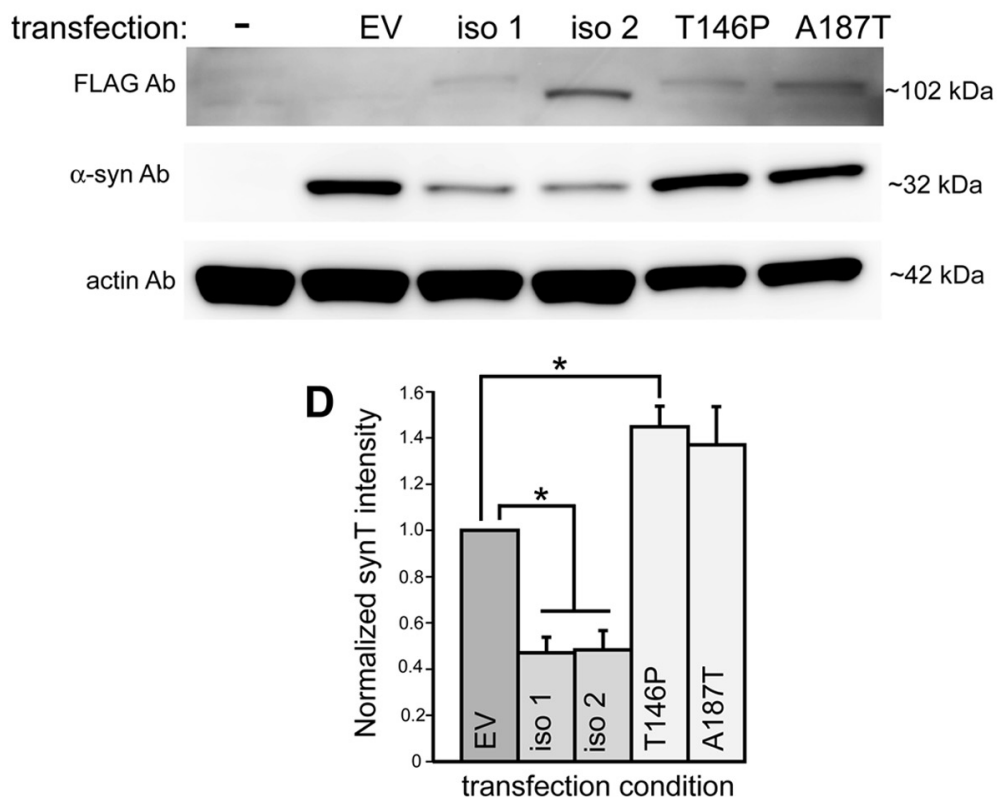

Figure 7. Overexpression of hVPS41 in H4 cells reduces the level of overexpressed $\alpha$-syn/truncated GFP. $\boldsymbol{A}$, Representative Western blot of protein levels in $\mathrm{H} 4$ cells transfected with synT, synphilin, and either empty vector (EV) control or hVPS41 isoform 1. A total of $10 \mu \mathrm{g}$ of total cell protein was resolved using SDS-PAGE, transferred to PVDF membrane, and immunoblotted using primary antibodies against FLAG (for hVPS41), $\alpha$-syn, or actin (loading control). The normalized intensity values of synT ( $\alpha$-syn) are reported below the blot image. Data analysis using Multigauge software revealed $\sim 45 \%$ decrease in synT ( $\sim 32 \mathrm{kDa}$ ) levels when hVPS41 ( $\sim 102 \mathrm{kDa}$ ) was being coexpressed. $B$, Semiquantitative RT-PCR of transfected $\mathrm{H} 4$ cells reveals that the transcriptional level of $\alpha$-syn is not being altered between the empty vector control and hVPS41-expressing cells. HPRT-1 was used as an internal loading control. C, Overexpression of hVPS41 SNPs in H4 cells fails to reduce the level of overexpressed synT protein. Representative Western blot of protein levels in transfected $\mathrm{H} 4$ cells was performed as described above $(\boldsymbol{A})$. Reduced synT ( $\sim 32 \mathrm{kDa}$ ) levels compared with EV were observed when hVPS41 isoform 1 ( $\sim 102 \mathrm{kDa}$ ) or hVPS41 isoform 2 ( 100 kDa) are coexpressed. Expression of either hVPS41 SNP ( 102 kDa) failed to reduce the level of synT ( $\sim 32 \mathrm{kDa}$ ) compared with EV, supporting functional defects associated with these SNPs. D, The normalized intensity values of synT ( $\alpha$-syn) were compared between the various hVPS41 constructs and the EV control. Data analysis using Multigauge software revealed a 53\% and $\sim 52 \%$ decrease in synT levels compared with EV when hVPS41 isoform 1 or hVPS41 isoform 2 are coexpressed, respectively. When either SNP is present in hVPS41, an increase in synT level is observed when compared with EV. Results represent data collected from three independent experiments. Data are reported as the mean \pm SD. ${ }^{*} p<0.05$, Student's $t$ test.

genetic background of RNAi-resistant sid-1 mutant animals. The use of neuron-specific RNAi in animals resistant to RNAi in other cell types enables cell-specific depletion of genes that are otherwise lethal to the nematode when knocked down in all cell types. Genetic knockdown of the AP-3 $\delta$-subunit or HOPS complex (VPS-39 and VPS-41) either pan-neuronally or selectively in the dopaminergic neurons significantly enhanced degeneration in worms expressing $\alpha$-syn. In this manner, the pan-neuronal RNAi strain served to validate the results obtained using the dopaminergic neuron-specific $\mathrm{RNAi}$, and also confirm that overexpression of an additional gene in the dopaminergic neurons does not simply alter the level of $\alpha$-syninduced neurodegeneration through decreased transgene expression. These data reveal the importance of Golgi-lysosomal trafficking in regulating cellular toxicity elicited by $\alpha$-syn overex- pression and identify the cellular pathway in which hVPS41 is acting to protect neurons against $\alpha$-syn-induced neurodegeneration. Moreover, the development of transgenic nematodes enabling neuron-specific RNAi allows for postembryonic phenotypic evaluation of essential gene products, such as VPS-41, for which mutant animals are not viable (Lackner et al., 2005).

With the rapid advancement in genome sequencing technologies, numerous SNPs have been identified within the general human population, yet limited reports have emerged on the functional implications of such variation or their mechanistic implications for neurodegenerative, and other, diseases. In this context, the two SNPs, T146P and A187T, that have been identified within the WD40 domain of hVPS41 represent such an uncharacterized example. Here we report that when either SNP is introduced into the WD40 domain of hVPS41, the modified protein failed to protect cells against $\alpha$-syn accumulation (in $\mathrm{H} 4$ cells) and toxicity (in C. elegans dopaminergic neurons). These results correlate to our structure/ function analysis, wherein we also showed that the WD40 domain was required to maintain neuroprotection against $\alpha$-syn-induced dopaminergic neurodegeneration. Both of these SNPs have a minor allelic frequency of $f=$ 0.02 , indicating that only a small percentage of the general population contains either polymorphism. With only $5-10 \%$ of PD cases having a known genetic mutation, these SNPs may indicate susceptibility factors that possibly sensitize individuals to environmental or genetic cues promoting the onset or progression of PD. The molecular effect of these SNPs on hVPS41 may prevent hVPS41 from interacting with the AP-3 complex, recruiting of the HOPS complex, or activating the vacuolar RAB7 to promote lysosomal fusion. Further protein interaction studies will need to be conducted to clarify the molecular mechanism underlying the functional effect of these variants. Likewise, as with the recent PARK16/RAB7 finding, it will be interesting to determine whether additional modifying polymorphisms are uncovered within this pathway as disease-associated genomic datasets expand among patient populations.

In this study, we exploited the strengths of both invertebrate and cellular models of PD to functionally analyze the neuroprotective property of the lysosomal trafficking protein hVPS41. Together, these data reveal the cellular mechanism by which hVPS4 1 is acting to protect neurons from $\alpha$-syn accumulation and toxicity, and to identify two SNPs in hVPS41 that may enhance the susceptibility of PD pathology within certain populations. Overall, our data support hVPS41 as a potential therapeutic target for treating the progression of PD. This 
strategy serves as an example by which the experimental paradigm of model systems can be expanded to evaluate functional consequences of human genomic variation and prospective disease-modifying factors.

\section{References}

Brett CL, Plemel RL, Lobinger BT, Vignali M, Fields S, Merz AJ (2008) Efficient termination of vacuolar Rab GTPase signaling requires coordinated action by a GAP and a protein kinase. J Cell Biol 182: $1141-1151$.

Cabrera M, Ostrowicz CW, Mari M, LaGrassa TJ, Reggiori F, Ungermann C (2009) Vps41 phosphorylation and the Rab Ypt7 control the targeting of the HOPS complex to endosomes-vacuole fusion sites. Mol Biol Cell 20:1937-1948.

Calixto A, Chelur D, Topalidou I, Chen X, Chalfie M (2010) Enhanced neuronal RNAi in C. elegans using SID-1. Nat Methods 7:554-559.

Cao S, Gelwix CC, Caldwell KA, Caldwell GA (2005) Torsin-mediated neuroprotection from cellular stresses to dopaminergic neurons of C. elegans. J Neurosci 25:3801-3812.

Chu Y, Kordower JH (2007) Age-associated increases of alpha-synuclein in monkeys and humans are associated with nigrostriatal dopamine depletion: is this the target for Parkinson's disease? Neurobiol Dis 25:134-149.

Cooper AA, Gitler AD, Cashikar A, Haynes CM, Hill KJ, Bhullar B, Liu K, Xu K, Strathearn KE, Liu F, Cao S, Caldwell KA, Caldwell GA, Marsischky G, Kolodner RD, Labaer J, Rochet JC, Bonini NM, Lindquist S (2006) Alpha-synuclein blocks ER-Golgi traffic and Rab1 rescues neuron loss in Parkinson's models. Science 313:324-328.

Cuervo AM, Stefanis L, Fredenburg R, Lansbury PT, Sulzer D (2004) Impaired degradation of mutant alpha-synuclein by chaperone-mediated autophagy. Science 305:1292-1295.

Darsow T, Katzmann DJ, Cowles CR, Emr SD (2001) Vps41p function in the alkaline phosphatase pathway requires homo-oligomerization and interaction with AP-3 through two distinct domains. Mol Biol Cell $12: 37-51$.

Gitler AD, Bevis BJ, Shorter J, Strathearn KE, Hamamichi S, Su LJ, Caldwell KA, Caldwell GA, Rochet JC, McCaffery JM, Barlowe C, Lindquist S (2008) The Parkinson's disease protein alpha-synuclein disrupts cellular Rab homeostasis. Proc Natl Acad Sci U S A 105:145-150.

Gitler AD, Chesi A, Geddie ML, Strathearn KE, Hamamichi S, Hill KJ, Caldwell KA, Caldwell GA, Cooper AA, Rochet JC, Lindquist S (2009) Alpha-synuclein is part of a diverse and highly conserved interaction network that includes PARK9 and manganese toxicity. Nat Genet 41:308-315.

Hamamichi S, Rivas RN, Knight AL, Cao S, Caldwell KA, Caldwell GA (2008) Hypothesis-based RNAi screening identifies neuroprotective genes in a Parkinson's disease model. Proc Natl Acad Sci U S A 105:728-733

Harrington AJ, Knight AL, Caldwell GA, Caldwell KA (2011) Caenorhabditis elegans as a model system for identifying effectors of $\alpha$-synuclein misfolding and dopaminergic cell death associated with Parkinson's disease. Methods 53:220-225.

Hermann GJ, Schroeder LK, Hieb CA, Kershner AM, Rabbitts BM, Fonarev P, Grant BD, Priess JR (2005) Genetic analysis of lysosomal trafficking in Caenorhabditis elegans. Mol Biol Cell 16:3273-3288.

Hobert O (2002) PCR fusion-based approach to create reporter gene constructs for expression analysis in transgenic C. elegans. Biotechniques 32:728-730.

Inoue T, Thomas JH (2000) Targets of TGF-beta signaling in Caenorhabditis elegans dauer formation. Dev Biol 217:192-204.

Irizarry MC, Growdon W, Gomez-Isla T, Newell K, George JM, Clayton DF, Hyman BT (1998) Nigral and cortical Lewy bodies and dystrophic nigral neuritis in Parkinson's disease and cortical Lewy body disease contain alpha-synuclein immunoreactivity. J Neuropathol Exp Neurol 57:334-337.

Karpinar DP, Balija MB, Kügler S, Opazo F, Rezaei-Ghaleh N, Wender N, Kim HY, Taschenberger G, Falkenburger BH, Heise H, Kumar A, Riedel D, Fichtner L, Voigt A, Braus GH, Giller K, Becker S, Herzig A, Baldus M, Jäckle H, et al. (2009) Pre-fibrillar alpha-synuclein variants with impaired beta-structure increase neurotoxicity in Parkinson's disease models. EMBO J 28:3256-3268.

Komatsu M, Waguri S, Chiba T, Murata S, Iwata J, Tanida I, Ueno T, Koike
M, Uchiyama Y, Kominami E, Tanaka K (2006) Loss of autophagy in the central nervous system causes neurodegeneration in mice. Nature 441:880-884.

Kuwahara T, Koyama A, Gengyo-Ando K, Masuda M, Kowa H, Tsunoda M, Mitani S, Iwatsubo T (2006) Familial Parkinson mutant alphasynuclein causes dopamine neuron dysfunction in transgenic Caenorhabditis elegans. J Biol Chem 281:334-340.

Lackner MR, Kindt RM, Carroll PM, Brown K, Cancilla MR, Chen C, de Silva H, Franke Y, Guan B, Heuer T, Hung T, Keegan K, Lee JM, Manne V, O'Brien C, Parry D, Perez-Villar JJ, Reddy RK, Xiao H, Zhan $\mathrm{H}$, et al. (2005) Chemical genetics identifies Rab geranylgeranyl transferase as an apoptotic target of farnesyl transferase inhibitor. Cancer Cell 7:325-336.

Lakso M, Vartiainen S, Moilanen AM, Sirviö J, Thomas JH, Nass R, Blakely RD, Wong G (2003) Dopaminergic neuronal loss and motor deficits in Caenorhabditis elegans overexpressing human alpha-synuclein. J Neurochem 86:165-172.

McLean PJ, Kawamata H, Hyman BT (2001) alpha-Synuclein-enhanced green fluorescent protein fusion proteins form proteasome sensitive inclusions in primary neurons. Neuroscience 104:901-912.

McVey Ward D, Radisky D, Scullion MA, Tuttle MS, Vaughn M, Kaplan J (2001) hVPS41 is expressed in multiple isoforms and can associate with vesicles through the RING-H2 finger motif. Exp Cell Res 267:126-134.

Polymeropoulos MH, Lavedan C, Leroy E, Ide SE, Dehejia A, Dutra A, Pike B, Root H, Rubenstein J, Boyer R, Stenroos ES, Chandrasekharappa S, Athanassiadou A, Papapetropoulos T, Johnson WG, Lazzarini AM, Duvoisin RC, Di Iorio G, Golbe LI, Nussbaum RL (1997) Mutation in the alphasynuclein gene identified in families with Parkinson's disease. Science 276:2045-2047.

Qiao L, Hamamichi S, Caldwell KA, Caldwell GA, Yacoubian TA, Wilson S, Xie ZL, Speake LD, Parks R, Crabtree D, Liang Q, Crimmins S, Schneider L, Uchiyama Y, Iwatsubo T, Zhou Y, Peng L, Lu Y, Standaert DG, Walls $\mathrm{KC}$, et al. (2008) Lysosomal enzyme cathepsin $\mathrm{D}$ protects against alphasynuclein aggregation and toxicity. Mol Brain 1:17.

Radisky DC, Snyder WB, Emr SD, Kaplan J (1997) Characterization of VPS41, a gene required for vacuolar trafficking and high-affinity iron transport in yeast. Proc Natl Acad Sci U S A 94:5662-5666.

Ramirez A, Heimbach A, Gründemann J, Stiller B, Hampshire D, Cid LP, Goebel I, Mubaidin AF, Wriekat AL, Roeper J, Al-Din A, Hillmer AM, Karsak M, Liss B, Woods CG, Behrens MI, Kubisch C (2006) Hereditary parkinsonism with dementia is caused by mutations in ATP13A2, encoding a lysosomal type 5 P-type ATPase. Nat Genet 38:1184-1191.

Rehling P, Darsow T, Katzmann DJ, Emr SD (1999) Formation of AP-3 transport intermediates requires Vps41 function. Nat Cell Biol 1:346-353.

Ruan Q, Harrington AJ, Caldwell KA, Caldwell GA, Standaert DG (2010) VPS41, a protein involved in lysosomal trafficking, is protective in Caenorhabditis elegans and mammalian cellular models of Parkinson's disease. Neurobiol Dis 37:330-338.

Shin Y, Klucken J, Patterson C, Hyman BT, McLean PJ (2005) The cochaperone carboxyl terminus of Hsp70-interacting protein (CHIP) mediates alpha-synuclein degradation decisions between proteasomal and lysosomal pathways. J Biol Chem 280:23727-23734.

Simón-Sánchez J, Schulte C, Bras JM, Sharma M, Gibbs JR, Berg D, PaisanRuiz C, Lichtner P, Scholz SW, Hernandez DG, Krüger R, Federoff M, Klein C, Goate A, Perlmutter J, Bonin M, Nalls MA, Illig T, Gieger C, Houlden $\mathrm{H}$, et al. (2009) Genome-wide association study reveals genetic risk underlying Parkinson's disease. Nat Genet 41:1308-1312.

Singleton AB, Farrer M, Johnson J, Singleton A, Hague S, Kachergus J, Hulihan M, Peuralinna T, Dutra A, Nussbaum R, Lincoln S, Crawley A, Hanson M, Maraganore D, Adler C, Cookson MR, Muenter M, Baptista M, Miller D, Blancato J, et al. (2003) Alpha-synuclein locus triplication causes Parkinson's disease. Science 302:841.

Spillantini MG, Schmidt ML, Lee VM, Trojanowski JQ, Jakes R, Goedert M (1997) Alpha-synuclein in Lewy bodies. Nature 388:839-840.

Su LJ, Auluck PK, Outeiro TF, Yeger-Lotem E, Kritzer JA, Tardiff DF, Strathearn KE, Liu F, Cao S, Hamamichi S, Hill KJ, Caldwell KA, Bell GW, Fraenkel E, Cooper AA, Caldwell GA, McCaffery JM, Rochet JC, Lindquist S (2010) Compounds from an unbiased chemical screen reverse both ER-to-Golgi trafficking defects and mitochondrial dysfunction in Parkinson's disease models. Dis Model Mech 3:194-208. 
Swetha MG, Sriram V, Krishnan KS, Oorschot VM, ten Brink C, Klumperman J, Mayor S (2011) Lysosomal membrane protein composition, acidic $\mathrm{pH}$ and sterol content are regulated via a Light-dependent pathway in metazoan cells. Traffic 12:1037-1055.

Tucci A, Nalls MA, Houlden H, Revesz T, Singleton AB, Wood NW, Hardy J, Paisán-Ruiz C (2010) Genetic variability at the PARK16 locus. Eur J Hum Genet 18:1356-1359.

van Ham TJ, Thijssen KL, Breitling R, Hofstra RM, Plasterk RH, Nollen EA (2008) C. elegans model identifies genetic modifiers of alpha-synuclein inclusion formation during aging. PLoS Genet 4:e1000027.
Webb JL, Ravikumar B, Atkins J, Skepper JN, Rubinsztein DC (2003) Alpha-synuclein is degraded by both autophagy and the proteasome. J Biol Chem 278:25009-25013.

Winslow AR, Chen CW, Corrochano S, Acevedo-Arozena A, Gordon DE, Peden AA, Lichtenberg M, Menzies FM, Ravikumar B, Imarisio S, Brown S, O'Kane CJ, Rubinsztein DC (2010) $\alpha$-Synuclein impairs macroautophagy: implications for Parkinson's disease. J Cell Biol 190:1023-1037.

Yacoubian TA, Slone SR, Harrington AJ, Hamamichi S, Schieltz JM, Caldwell KA, Caldwell GA, Standaert DG (2010) Differential neuroprotective effects of 14-3-3 proteins in models of Parkinson's disease. Cell Death Dis 1:e2. 